\title{
YESTERDAY, TODAY AND TOMORROW:THE BLOSSOMING ART OF TEACHING AND LEARNING REQUIRED TO PREPARE STUDENTS FOR THE 4TH INDUSTRIAL REVOLUTION
}

\author{
Ignatius G. P. Gous, University of South Africa, South Africa
}

\begin{abstract}
The future is not what it used to be. It is more complex than ever, and it changes faster than ever. Traditional educational institutions do not teach the skills sets students need to be future ready. Most of them still follow the industrial model that focuses on content and testing answers about known questions. Research reports point to ways in which higher education needs to change to meet the challenges, such as teaching abilities instead of content, becoming network universities, my-universities, or life-long universities. The time frame expected to change the current systems and structures are between 5 and 10 years. That is too long. The future is now. Distance Education, though, can make an immediate difference. Departing from the premise that "I learn for a reason", grounded in the Golden Spiral for Life-Long Learning model, the way Distance Education teaches may become sufficient to engender future readiness. The future requires students with specific personal characteristics and abilities, linked to effective mastery strategies, and being open to the future and change. A lesson structure and flow is suggested, based on a combination of triedand-tested teaching and current mind, brain, and education research. Using the Brunfelsia Pauciflora "Floribunda" plant as metaphor, also called the Yesterday-today-and-tomorrow plant, the past, the present and the future are juxtaposed in an organic whole. In this way, a balanced approach is reached, that still attends to indispensable past knowledge and current application, but adding a required future ready perspective.
\end{abstract}

\section{Introduction}

"The future is not what it used to be!" This is an old saying, probably true since time immemorial, pronouncing several shades of feelings of uncertainty about what is to happen in the future, and especially how we are to prepare for it (see a well-researched history of the saying by Garson, 2012). Fact is, the future is looming large, and we are on the cusp of a new era and at the start of the $4^{\text {th }}$ Industrial Revolution. Artificial Intelligence and automation, for one, is already changing our worlds and the workplace. Many reports about expected changes are seeing the light, as well as contemplations about future ready schools and curricula.

Aligned to this is the question whether Education, and Online Education in particular, is preparing our students for the futures they are being faced with. Are we delivering future 
ready students? Are our courses and curricula imparting the kinds of knowledge and skills our students need to cope in years to come?

This paper is a concise literature review about the kinds of skills, knowledge and attitudes students need to manage the future. A brief overview of reports and books on future expectations is presented, followed by a focus on students' skills in terms of identity, mastery and legacy. The latter classification stems from my research on effective learning strategies, which was translated into a program called the Golden Spiral of Lifelong Learning, presented in schools, universities and the workplace (Gous, 2018), and is worded in the mantra "I learn for a reason".

The conclusion is that our teaching and learning should cultivate something akin to the plant Brunfelsia Pauciflora "Floribunda". It is a plant with sweet-smelling flowers in three shades carried simultaneously, which changes from one day to the next. It starts off being deep purple, then change to pale lavender blue, and finally becomes pale white - hence the name "yesterday-today-and-tomorrow". Each subject that we teach, has a disciplinary history and growth - in German it is called the "Forschungsgeschichte". It also has a focus on current applicability and relevance, requiring answers to known questions and preparing learners for their worlds of work. These two aspects are getting ample attention in present-day teaching and learning. The aspect of "tomorrow", however, is not always part of the curriculum, probably because there is so much to learn from yesterday and a lot to apply today, that there is not enough time to focus on tomorrow. It may also be that tomorrow is too vague and unknown to receive a lot of attention. The changing world and the half-life of knowledge, however, is forcing us to reconsider these practices.

Learners also comes with a yesterday, a today and a tomorrow. They have yesterdays in terms of personal histories and situatedness. They too have a today to get through in terms of mastery and application of knowledge. They will have to manage all their tomorrows, which will dawn onto them earlier than they might think.

With Distance and Online learning set to become all the more important, the question is whether it will be able to juxtapose all three aspects, especially to add a focus on the future. With distance education students coming from often radically diverse yesterdays, and with widely differing challenges facing them today, it is very perplexing to decide which of the unknown tomorrows to cater for. The spectrum of colours to blossom into will have to be more than just three - but the question is how to do it when your students are at a transactional distance?

\section{"The Future is not what is used to be"}

We are on the cusp of a new era and at the start of the $4^{\text {th }}$ Industrial Revolution. According to a report on the World Economic Forum, changes in the workplace is going to create in twelve years' time - the time it takes a child to complete school - between 400 to 800 million people who will need to be retrained and reskilled because their jobs have become obsolete. Research 
on the half-life of qualifications have shown that people who complete their degrees now, will have a half-life of their knowledge that necessitates 5 to 6 hours per week of dedicated and serious learning just to keep abreast of new developments in their fields.

Several reports and publications have been generated on expected disruptive changes in the workplace over the next 3 to 32 years. In the World Economic Forum report published in 2018 called "Eight Futures of Work: Scenarios and their Implications" the changing world of work is mentioned.

Several factors contribute to the expected changes. Technology is the most important. Automation, robotics and artificial intelligence are bound to make some jobs obsolete, change some others, and create some jobs that do not exist yet. The world, which has become a global village, creates mobile and migratory labour and brings about demographic changes. Education changes in the sense that face-to-face institutions do not have monolithic student populations any more, which has been a characteristic for distance education and online education for a long time. All of this brings about that the talent needs of workers are changing and expanding.

As a result of this, a 2018 report on "The Future of Jobs" the World Economic Forum (WEF) points to the need of re- and up-skilling of workers, brought about by changes in the workplace. According to the report, by 2022, a mere 3 years from now, $54 \%$ of all workers will need significant reskilling and upskilling. These will range from additional education and training of up to 6 months (35\% of workers), up to 12 months (9\% of workers), or more than a year ( $10 \%$ of workers). The kind of knowledge and skills that the will need additional skilling in, will be basic mastery of new developments in their fields, but also aspects such as innovation, analytical thinking, as well as active learning and learning strategies.

In terms of what is being expected to happen in Africa, a 2017 report by the WEF "The Future of Jobs and skills in Africa - Preparing the region for the Fourth Industrial Revolution" points to the influence of automation on work. The predict that more than $40 \%$ of all work activities in Africa are vulnerable to automation - 41\% in South Africa, $44 \%$ in Ethiopia, $46 \%$ in Nigeria and 52\% in Kenya, even though it may be toned-down by low labour costs and counterbalanced by the creation of new jobs. Even so, the report underscores the need of skilling and re-skilling in Africa. In South Africa, by 2020 39\% of core skills required across occupations will be entirely different. $41 \%$ of firms in Tanzania, 30\% in Kenya, $9 \%$ in South Africa and $6 \%$ in Nigeria are inadequately skilled, and this pattern is set to continue or may even get worse in the future.

Yuval Noah Harari (author of Sapiens, Homo Deus, and 21 Lessons for the $21^{\text {st }}$ century) predicts the emergence of a new class of people by 2050 . He calls them "the useless class" people who are not just unemployed, but unemployable. According to him, 
"... the big danger of the appearance of a useless class is not because of the absolute loss of jobs, it's because of the difficulty in retraining and reinventing yourself."

From this and other reports, it is clear that radical change in the world of work is not only inevitable, it is already happening. It is therefore important for educational institutions to take this into account in their teaching offerings, their curricula as well as the kind of skills they teach their students. The challenge for distance and online educational institutions is even bigger, in the light of their diverse student populations. What needs to be taught?

\section{The need for a different set of skills, added to content knowledge}

Curricula needs to include content that is up to date in terms of their discipline, relevant to their contexts and meaningful in terms of application. In addition to this, it needs to include the teaching of skills needed not only to master the prescribed content, but skills to become "future ready".

According to reports, "future readiness" entails aspects such as lifelong learning skills, cognitive flexibility, creativity, critical thinking, and emotional intelligence, and not merely mastering content by means of rote learning. According to the 2017 White Paper by the World Economic Forum titled "Realizing Human Potential in the Fourth Industrial Revolution: An Agenda for Leaders to Shape the Future of Education, Gender and Work", education should be thoroughly reimagined to include the following:

- expanded access to early-childhood education;

- ensuring the 'future-readiness' of curricula;

- investing in developing and maintaining a professionalized teaching workforce;

- early exposure to the workplace and career guidance;

- investing in digital fluency and ICT literacy skills;

- providing robust and respected technical and vocational education and training (TVET);

- creating a culture of lifelong learning; and

- openness to education innovation.

It is clear that current curricular content and educational offerings need to be expanded and augmented. It calls for a balancing act between the past and current disciplinary content, but also a future oriented openness, and readiness for content that is developing or not even developed. The only way to prepare for something that is still unknown, is to empower students with skills, habits, attitudes and abilities to master new knowledge as it emerges.

Research on the half-life of qualifications have shown that people who complete their degrees now, will have a half-life of their knowledge that necessitates 5 to 6 hours per week of dedicated and serious learning just to keep abreast of new developments in their fields. 
In 2017 Deloitte brought out a report called "The 2017 Deloitte Global Human Capital Trends: Rewriting the rules for the digital age". They surveyed more than 10,000 business and HR leaders from all over the world, focussing on the challenges ahead in an intensely changing demographic, social, digital and economic landscape. In the chapter "Careers and learning: Real time, all the time", they wrote:

"What does it mean to have a career today? More specifically, what does it mean in a world where careers span 60 years, even as the half-life of learned skills continues to fall to only about five years? In the past, employees learned to gain skills for a career; now, the career itself is a journey of learning."

"As companies build the organization of the future, continuous learning is critical for business success. For today's digital organizations, the new rules call for a learning and development organization that can deliver learning that is always on and always available over a range of mobile platforms."

Thomas and Brown (2011, CreateSpace) wrote in their book "A New Culture of Learning: Cultivating the Imagination for a World of Constant Change" that

$$
\begin{aligned}
& \text { "learning requires } \\
& \text { content - which can be taught, } \\
& \text { skill - which can be mentored, and } \\
& \text { disposition - which can be cultivated." }
\end{aligned}
$$

Ehlers and Kellerman (2019) published a report on "Future Skills - Future Learning and Future Higher Education", a Delphi survey of an international panel of 50 experts from academia and business. The survey evaluated the readiness of higher education institutions within the next 5 years to teach their students the kind of skills needed to be future ready. According to the experts, these institutions are not ready to teach in ways and develop curricula and systems to engender future skills that are becoming increasingly relevant and important.

Ehlers and Kellerman (2019; p.3) define future skills as "the ability to act successful on a complex problem in a future unknown context of action". It refers to an individual's disposition to act in a self-organised way, visible to the outside as performance.

They divided the future skills into three interrelated dimensions, namely a subjective dimension, an object dimension and a social dimension. The subjective dimension relates to an individual's subjective, personal abilities to learn, adapt and develop to be able to productively participate in the workforce of tomorrow, actively shape the future working environment and involve themselves into forming societies to cope with future challenges. The future skills linked to this are (2019; p.3):

- autonomy; 
- $\quad$ self-initiative;

- $\quad$ self-management;

- need / motivation for achievement;

- personal agility;

- autonomous learning competence; and

- self-efficacy.

The object dimension relates to an individual's ability to act self-organized in relation to an object, a task or a certain subject matter related issue. It is about mastering knowledge, but additionally to connect it to motivation, values and purpose, as well as using it in an organised way. The skills related to this are (2019; p.3):

- agility;

- creativity;

- tolerance for ambiguity;

- digital literacy; and

- ability to reflect.

The social dimension relates to an individual's ability to act self-organized in relation to its social environment, the society and organizational environment. The skill profiles are:

- sense-making;

- future mindset;

- cooperation skills; and

- communication competence.

The report also reflects about whether higher educational institutions are structurally ready and pedagogically able to teach and support the learning of these. They identify four aspects that need to change in institutions to be so.

The first is the future skill university, which redefines graduate attributes. The current "reduced / narrow focus on academic and valid knowledge acquisition as a means to provide correct answers for known questions based on a curriculum which is focused on defined skills for fixed professions" is to be replaced with a "next mode" of studying, with the focus on future skills, such as autonomous learning, self-organization, applying and reflecting knowledge, creativity and innovation (Ehlers \& Kellermann, 2019; pp.4-5).

The second is the networked multi-institutional study scenario, where higher education moves from a "one institution" model to a multi-institution one, providing qualifications through alliances of several institutions (2019; pp.4-5).

The third is the "my-university" scenario where students have the choice to build their own personalized curriculum. It is no longer a fully predefined and 'upfront' given structure, but rather a more flexible, personalized and participatory model in which students actively cooperate with professors / teachers / advisors in curriculum building of higher education programs (2019; pp.4-5). 
The fourth model is the lifelong higher learning scenario, where higher education institutions no longer focus on preparing students up front for future a profession, but compliment it with lifelong learning offerings (2019; pp.4-5).

The period for the adoption and implementation of these scenarios, are more than 10 years from now for the first three, and within the next 5 years for the fourth (Ehlers \& Kellermann, 2019; p.4).

To summarise, it is clear that traditional education focussed on the acquisition of past and current knowledge and skills. Existing knowledge and skills were taught to students, who had to learn and master them. The goal was to be able to apply them in present settings such as known jobs or careers. The new knowledge economy of the $21^{\text {st }}$ century questions the ability of this to deal with its complexities and rapidly changing nature. For this reason, the need to teach and learn other kinds of competencies emerged in order to help students become future ready. Because technologies are responsible for the rapid changes and complexities, the focus is often on teaching technological skills, as well as skills related to use technology to teach and learn. However, the realisation has dawned that personal attributes, characteristics and skills are equally important, and should also be taught and mastered.

The future is now. The future calls for different skills sets to be taught and acquired. Higher education institutions are not ready to provide it. Will Distance Education be able to do it sooner than 5 or 10 years?

\section{Future Ready Distance Education, Teaching and Learning}

Macro systems of Higher Education, such as accreditation of qualifications and curricula, are cumbersome to change. That is why any of the above suggestions will take as many as 10 years to put in place. It is clear and crucial that these changes should be attempted, and that it should be done as quickly as it is feasible. What is within reach to change immediately, though, is how we teach our subjects. It is right now within our locus of control to attend to the aspects of Identity, Mastery and Legacy in a single lecture, and by doing it, attend to the learners', the subject's and discipline's yesterdays, todays and tomorrows.

There are even some aspects of online and distance education that will make it easier to do than is the case at contact tuition institutions.

As has been pointed out, traditional teaching focuses on mastery of current knowledge, and assessing the mastery of known understanding. The development of the identity of the student, in other words their personality attributes and characteristics were seen as falling outside of the scope of practice of the institution and the lecturer. In similar vein, a focus on how the subject and discipline is going to change was also not a major concern. This was the case where students were present in face-to-face classes and often part of a homogenous group from similar contexts, aiming to apply their gained knowledge in comparable 
circumstances. Being at a distance, made it even more difficult or even impossible to personalise teaching and learning to all students.

The diverse student population hailing from dissimilar backgrounds and studying asynchronously is actually a positive aspect in terms of engendering future readiness. Lecturers who take it seriously that their students are from different contexts, will make sure that their content takes this into account, and that it has to be made relevant in meaningful in more contexts than the one from which the lecturer or the establishment hails.

With this reality clearly in mind, the way each lesson is taught can be planned, according to a scaffolding framework to make sure all relevant and important aspects are attended to. This framework is called The Golden Spiral for Life-Long Learning, and is based on aspects of learning as identified and practiced by age-old pedagogical wisdom, as well as current mind, brain, and education science.

Six broad aspects of learning are placed on a spiralling trajectory through a learning landscape. These six are (a) future perspective (dream), (b) planning, (c) the learning curve, (d) productive mistakes, (e) help and support, and (f) assessment of progression. A seventh aspect is present at each of these six, namely a metacognitive reflection on each of them on its own and all of them working together (Gous, 2018).

The point of departure is always the endpoint of the spiral, namely the future perspective. This is supported by the work of Wiggins and McTighe on backward planning. They compared two kinds of planning performed by students. Backward planning starts at the envisioned goals and outcomes and then formulates actions from a current point of departure. Forward planning starts at the point of departure, and plans actions steps towards the envisioned goal. While the action steps of the two groups of students were similar, the motivational value of backward planning outperformed the forward planners (McTighe \& Thomas, 2003; Wiggins, Wiggins, \& McTighe, 2005; Jones, Vermette, \& Jones, 2009; Wiggens \& McTighe, 2011).

Starting each lecture with the future in mind in terms of meaning and relevance is important for motivation to learn. Adding to this a focus on envisaged future developments in the discipline, field or subject, and how the current knowledge may contribute towards future change, is crucial to make students aware that they are responsible and able to create the future they want to see. In this way, the future blossoms concurrently become part of the past and present in an organic whole like the yesterday-today-and-tomorrow flowers.

Future studies in disciplines are just as important as the histories thereof. It is, however, just as specialised an area of research that needs to be mastered than becoming an expert in the subject, its history and applications itself. For this reason, it will be necessary for subject societies and professional bodies to devote special attention to envisaged future developments. This knowledge should be made available to educators to include in their lectures. 
Becoming future ready and future fit is the combined responsibility of all involved in the discipline - from the lecturers who should be at the forefront of knowledge mastery, to the students who have to make it part of their identity, to the professional discipline leaders who should keep an eye on the legacy.

An example in case is the teaching of economics. Tieleman (2019) shared some thoughts in The Conversation, arguing the case Why the world is due a revolution in economics education. Tieleman is a co-founder of Rethinking Economics in the Netherlands, and he does part-time work for a charity dedicated to a fairer, more sustainable economic system Our New Economy. According to him,

"Economic thinking governs much of our world. But the discipline's teaching is stuck in the past. Centred around antiquated 19th-century models built on Newtonian physics, economics treats humans as atomic particles, rather than as social beings."

Real world issues were not addressed, for example in the Netherlands, real-world problems, from climate change to inequality, were seriously treated in only $6 \%$ of all modules and that only $2 \%$ of methods courses were not focused on statistical work. He concludes:

"Let's hope that we don't have to wait for the present generation of economists to retire before this can happen. By that time, it might be too late."

This example show how people involved the field and knowledgeable about the discipline become future-oriented, advocating the teaching of their discipline in a way to get their students future-fit.

\section{Conclusion}

Like the Brunfelsia Pauciflora "Floribunda", also called the Yesterday-today-and-tomorrow plant, the past, the present and the future needs to be taught juxtaposed in an organic whole. In this way, a balanced approach is reached, that still attends to indispensable past knowledge and current application, but adding a required future ready perspective.

\section{References}

Ehlers, U.-D., \& Kellermann, S. A. (2019). Future Skills - The Future of Learning and Higher education. Results of the International Future Skills Delphi Survey. Karlsruhe. Retrieved from https://nextskills.org/future-skills-report-2019/

Garson (2012, December 6). The Future Is Not What It Used to Be. Quote Investigator [Blog post]. Retrieved from https://quoteinvestigator.com/2012/12/06/future-not-used/

Gous, I. G. P. (2018). Learning Explained: A schema-building scaffolding framework to make sense of personalized guidance and support for learning. In J. M. Duart, \& A. Szücs (Eds.), Towards personalized guidance and support for learning (pp. 289-311). 
Harari, Y. N. (2014). Sapiens: A brief history of humankind. Random House.

Harari, Y. N. (2016). Homo Deus: A brief history of tomorrow. Random House.

Harari, Y. N. (2018). 21 Lessons for the $21^{\text {st }}$ Century. Random House.

Jones, K. A., Vermette, P. J., \& Jones, J. L. (2009). An integration of “backwards planning” unit design with the "two-step" lesson planning framework. Education, 130(2), 357-361.

McTighe, J., \& Thomas, R. S. (2003). Backward design for forward action. Educational Leadership, 60(5), 52-55.

Tieleman, J. (2019, April 15). Why the world is due a revolution in economics education. The Conversation [Blog post]. Retrieved from https://theconversation.com/why-the-world-isdue-a-revolution-in-economics-education-112785

WEF (2017). Deloitte Global Human Capital Trends: Rewriting the rules for the digital age. White Paper. World Economic Forum.

WEF (2017). Realizing Human Potential in the Fourth Industrial Revolution: An Agenda for Leaders to Shape the Future of Education, Gender and Work. White Paper. World Economic Forum.

WEF (2017). The Future of Jobs and skills in Africa - Preparing the region for the Fourth Industrial Revolution. White Paper. World Economic Forum.

WEF (2018). Eight Futures of Work: Scenarios and their Implications. White Paper. World Economic Forum.

WEF (2018). The Future of Jobs. White Paper. World Economic Forum.

Wiggins, G., Wiggins, G. P., \& McTighe, J. (2005). Understanding by design. ASCD (Association for Supervision and Curriculum Development). 